\title{
CVI. The excitation of soft characteristic X-rays
}

\section{O.W. Richardson F.R.S. \& C.B. Bazzoni Ph.D.}

To cite this article: O.W. Richardson F.R.S. \& C.B. Bazzoni Ph.D. (1921) CVI. The excitation of soft characteristic X-rays , Philosophical Magazine Series 6, 42:252, 1015-1019, DOI: 10.1080/14786442108633840

To link to this article: http://dx.doi.org/10.1080/14786442108633840

\section{Published online: 08 Apr 2009.}

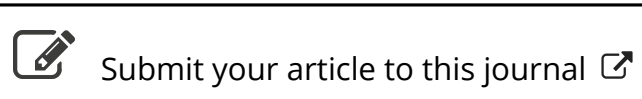

\section{Џ Article views: 4}

Q View related articles 두

Citing articles: 22 View citing articles 지 
the two components of $\mathrm{H}_{a}$. Witb ordinary resolving-power this appears as a single line, but the part due to $2 p_{1}-5 d$ is absent below the ionization potential.

The combination line $2 p_{2}-2 \mathrm{P}, \lambda 7587$, has never been observed in magnesium. If this represents a physically possible type of interorbital transition, it should accompany the two-line spectrum for, on referring to fig. 3 , it is seen that but three combinations could take place once an electron is in the $2 \mathrm{P}$ ring, viz. $1.5 \mathrm{~S}-2 \mathrm{P}, 2 p_{z}-2 \mathrm{P}$, and $1.5 \mathrm{~S}-2 p_{2}$. Certainly the conditions for the production of $2 p_{2}-2 \mathrm{P}$ are most favourable from the probability standpoint. Using dicyanin-stained plates having high sensitivity at this wavelength, $\lambda 7587$, the two-line spectrum was carefully photographed, but no trace of $\lambda 7587$ was present, the lines $\lambda 4571$ and $\lambda 2852$ appearing alone with pronounced intensity.

In conclusion, the writers desire to express their sincere thanks to Dr. Dushman of the General Electric Co., and to Dr. Rentschler, Dr. Shackelford, and Mr. Holden of the Westinghouse Lamp Company for furnishing them with essential parts to the apparatus used in the present experiment.

Bureau of Standards, Washington, D.C., May 18,1921 .

CVI. The Excitation of soft characteristic X-rays. By O. W. Richardson, F.R.S., Wheatstome Professor of Physics in the University of London, and C. B. BAzzonI, Ph.D., Professor of Physics in the University of Pennsylvania*.

r JHIS work was commenced by one of us (O. W. R.) 1 during the war as a development of our work on the limiting frequency in the spectra of helium, hydrogen, and mercury in the extreme ultra-violet + . It was planned to extend the use of the photoelectric spectroscope there described to the analysis of soft X-rays generally. However, the work had to be abandoned temporarily, and it has not been possible to resume it until recently.

The apparatus was of quartz glass, essentially the same as the one used in the work on helium already referred to. The eathode was of tungsten wire, and the anode and other electrodes included in the discharge chamber were of such

* Communicated by the Authors.

† Phil. Mag. vol. xxxiv. p. 285 (1917). 


\section{Profs. O. W. Richardson and C. B. Bazzoni on the}

dimensions and so insulated that they could easily be raised to a white heat or even melted down with the electron discharge from the cathode. The diffusion of ions from the discharge chamber to the detection chamber was prevented by a parallel plate condenser set in the slit-like tube connecting the two chambers. No windows or partitions were used. In order to render this method of protection against diffusion successful, particular relations of the potentials of the various electrodes were necessary. After the particular arrangement was reached through trial no difficulties from stray ions were encountered.

The radiations were stimulated by impact of electrons of known velocities on small targets of the element under investigation located similarly to $A_{1}$ of fig. 1 of our former paper (loc. cit. p. 288). It was soon obvious that the amount of radiation to be dealt with, as judged by its photoelectrie activity, was very much smaller. from the solid targers than when gases were used. It therefore became desirable before attempting any magnetic analysis of the photoelectric electrons to explore the conditions under which any radiation is generated, using some more sensitive method. We accordingly connected the box in the receiving chamber to the electrometer and looked for discontinuities in the negative current from it, due to the photoelectric effect of radiation falling on it, as the potential driving the electron current in the discharge chamber was gradually increased. It is, of course, an assumption that these increases are really due to radiation generated at the bombarded target, but we believe we have made subsidiary tests on this point which exclude every possible alternative. It is a further assumption which can only be defended by analogy with the known laws of production of $\mathrm{X}$-rays of higher frequency, that these photoelectrically active rays are really $X$-rays of frequency corresponding, on the quantum relation, to the voltage of the exciting discharge. It is our hope to be able to supply the proof or disproof of this by the magnetic or by an electrostatic method, but it is not possible to do this until a preliminary exploration of the conditions under which some sort of radiation is generated has been made. In the helium work the electrostatic method (loc. cit. p. 287) was discarded as hopeless, but with the radiation from solids the secondary effects which we then had to contend with may not be so serious.

The success of the measurements depends, amongst other things, on obtaining and maintaining a vacuum as nearly perfect as possible, since the radiations set up from gas 
molecules appear at lower voltages than those from the target and, if any considerable amount of gas is present, completely swamp the effect sought. The device was therefore exhausted with the most extreme precautions and, protected by two liquid-air traps, was held constantly on a very fast diffusion pump throughout the measurements. The electrodes in the discharge chamber were so related that they could be used as an ionization manometer, and the pressure fluctuations in the immediate neighbourhood of the target followed during the observations. The pressure during the runs recorded below was of the order $10^{-8}$ to $10^{-9} \mathrm{~mm}$.

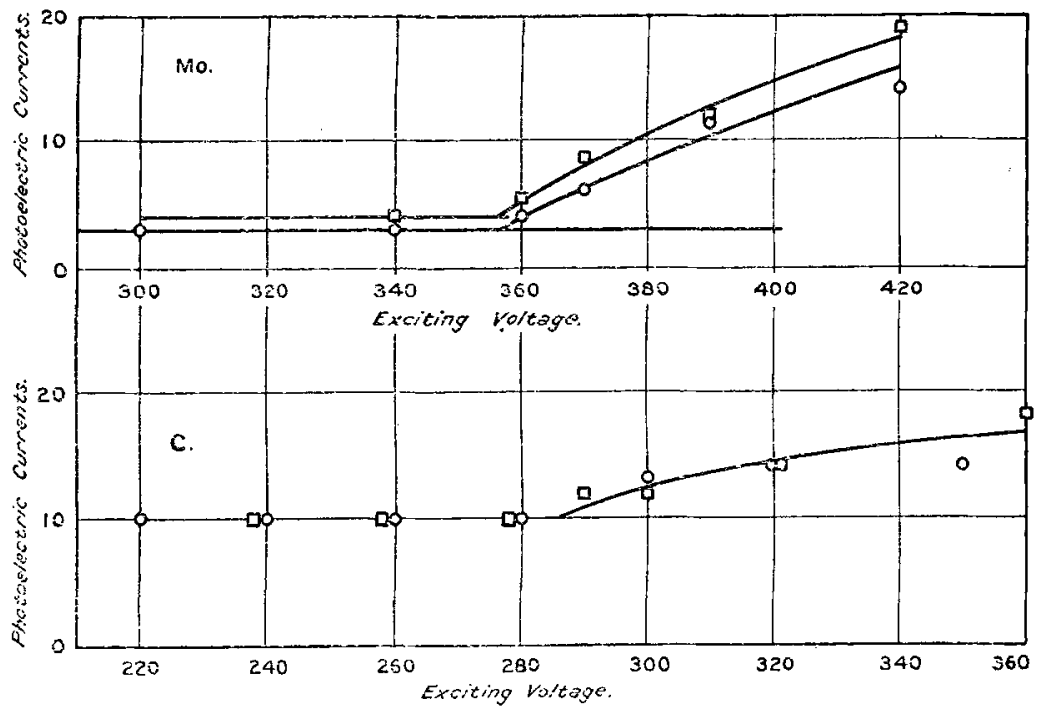

The emission of raliation has been detected with carbon, molybdenum, copper, and tungsten targets. In the case of carbon and molybdenum, the critical potential at which the radiation sets in has been determined with considerable exactness, as will be seen from the sample data plotted in the accompanying diagram. The details of the experiments with these two elements are as follows :-

CARBon.-The target was prepared by precipitating carbon on a copper disk from a solution of india-ink. A smooth coherent deposit was obtained. In making the observations, the exciting thermoionic current was kept constant by reducing the temperature of the filament as the operating voltage was increased. Although the pressure was of the order $10^{-8}$ to $10^{-9} \mathrm{~mm}$., a radiation effect was present at

Phil. Mag. S. 6. Vol. 42. No. 252. Dec. 1921. $3 \mathrm{X}$ 


\section{The Eivcitation of soft characteristic X-rays.}

220 volts, which may have been due to residual gas as it was independent of the voltage above 220 volts, under the working conditions. The curre shows the setting-in of new radiation at 286 volts. The points marked $O$ were taken with rising, and those marked $\square$ with falling potentials. The observations are consistent with each other, showing that the rise in the current is not, due to a generation of gas as the potential is raised. The voltages were measured with reference to the negative end of the filament, and the voltage drop along this was between 6 and 7 volts in all the experiments.

The defexions due to this characteristic radiation from carbon were rather small, and some of the points do not fall very well on the curve drawn. Nevertheless, they are sufficient to determine the critical voltage and, assuming the quantum relation to hold good, the wave-lengths of the radiation pretty accurately. Numerous independent tests showed that there was no increase at 280 volts and a measurable increase at 300 . The reading at 290 is not so certain. We believe, however, that it is impossible for the uncorrected exciting voltage to lie outside the limits 280 290 volts, and it is probably close to 286 . There are two corrections-one for the drop of potential in the hot filament and the other for the work done on the electron when it passes into the anode. These cancel one another in this case to within about 1 volt, which is about as accurately as they can be estimated. If we admit that these radiations are soft $X$-rays excited according to the same laws as hard $X$-rays and apply the quantum relation, we find that the wavelength of the shortest member of the group must lie between the limits $4 \% \cdot 7$ and $44 \cdot 3 \AA$.U., and is probably very close to 43.4 A.U. Extrapolating from $\mathrm{K}_{\beta}$ for Al, using Moseley's relation, we find that $K_{\beta 3}$ for carbon should have a wavelength of $45.5 \AA$ A.U., and from a formula given by Uhler * $50.25 \AA$ A. U. It is thus practically certain that we are dealing here with the $\mathrm{K} X$-rays from carbon, although, as has already been pointed out, we are not yet able to supply a direct proof that the radiations generated are actually K X-rays.

Molybuentm.--The target was cut from a sheet of pure molybdenum. The false zero line attributed provisionally to gals was lower and the vacuum steadier than in the work with carbon, probably because of the higher temperatures (above the melting-point of copper) attained in the cleanups. Two ont of a number of sets of readings, all of which were concordant, are shown in the figure. The voltage drop

* Phys. Rev. vol. ix. p. 325 (1917). 
down in the filament varied between 6 and 8 volts during these experiments. The curves show radiation setting in at 356 volts. It is difficult to see how this point can lie outside the limits 354-358 volts in view of these experiments. As in the case of carbon, the two corrections practically cancel each other. The corresponding wave-length limits are $34 \cdot 6$ to $35 \cdot 0 \AA$.U. and the probable value $34 \cdot 8 \AA$.U. Calculating from an empirical formula given by Vegard* for the $M_{\alpha}$ line,

$$
\nu / R={ }_{144}^{7} \mathrm{~N}^{2}-2 \cdot 37 \mathrm{~N}+40,
$$

where $\nu$ is the frequency, $\mathbf{R}$ Rydberg's constant, and $\mathbf{N}$ the atomic number, the extripolated wave-length for the $M \alpha$ line for molybdenum is found to be $35.2 \AA$.U. As we should expect the radiations to be excited by a voltage corresponding to a frequency somewhat higher than that of the a line of the series, we see that there is good ground for identifying the phenomena here investigated with the excitation of the M X-rays of molybdenum.

The ultimate objective of the experiments is to examine the frequencies of the emilted radiations by measuring the energy of the electrons which they liberate by photoelectric action. We believe that this apparatus is capable of giving the desired infurmation, and the work is being carried forward at the present time. During the past three years similar measurements have been made by one of us (C. B. B.) on sodium, potassium, and lithium, on which it is hoped shortly to publish results. During 1919-20 some tests were made in the Wheatstone Laboratory by Mr. G. Williamson, using lithium salts and carbon, and by Dr. Holtsmark with earbon. Whilst these experiments did not lead to results which seemed unequirocal, we feel that we have probably profited through the experience gained thereby.

CVII. Remark concerning Professor Vegard's Paper entitled "Recent Results of Northlight Investigations and the Nature of the Cosmic Electric Rays." By Professor CARL Störmer, Christiania $\dagger$.

T $N$ consequence of a paper appearing under the above title 1 in the Philosophical Magazine for July, 1921, I beg to draw attention to the work I have recently completed, and which appeared at the beginning of July last in Geofysiske Publikationer, vol. 1. No. 5, Christiania, under the title "Rapport sur une expédition d'aurores boréales à Bossekop et Store Korsnes pendant le printemps de l'annéo 1913," 269 pages with 104 plates.

* Phil. Mag. vol. xxxv. p. 316 (1918).

t Communicated by the Author. 